\title{
Tower Crane Location Optimization for Heavy Unit Lifting in High-Rise Modular Construction
}

\author{
Hosang Hyun ${ }^{1}$, Moonseo Park ${ }^{2}$, Dowan Lee ${ }^{3}$ and Jeonghoon Lee ${ }^{4, *}$ \\ 1 Department of Seoul Housing Urban Research Center, Seoul Housing and Communities Corporation, \\ Gaepo-ro 621, Gangnam-gu, Seoul 06336, Korea; hhs518@i-sh.co.kr \\ 2 Department of Architecture and Architectural Engineering, Seoul National University, Gwanak-ro 1, \\ Gwanak-gu, Seoul 08826, Korea; mspark@snu.ac.kr \\ 3 ROKAF Education and Training Command, 46, Songbaek-ro, Geumsan-myeon, Jinju-si, \\ Gyeongsangnam-do 52634, Korea; genus39@hotmail.com \\ 4 Department of Architecture Engineering, Gyeongsang National University, Dongiin-ro, Junju-si, \\ Gyeongnam 52725, Korea \\ * Correspondence: jhleepro@gnu.ac.kr
}

check for updates

Citation: Hyun, H.; Park, M.; Lee, D.; Lee, J. Tower Crane Location Optimization for Heavy Unit Lifting in High-Rise Modular Construction Buildings 2021, 11, 121. https:// doi.org/10.3390/buildings11030121

Academic Editor: Carlos

Oliveira Cruz

Received: 4 February 2021

Accepted: 16 March 2021

Published: 18 March 2021

Publisher's Note: MDPI stays neutral with regard to jurisdictional claims in published maps and institutional affiliations.

Copyright: (c) 2021 by the authors. Licensee MDPI, Basel, Switzerland. This article is an open access article distributed under the terms and conditions of the Creative Commons Attribution (CC BY) license (https:// creativecommons.org/licenses/by/ $4.0 /)$.

\begin{abstract}
Modular construction, which involves unit production in factories and on-site work, has benefits such as low cost, high quality, and short duration, resulting from the controlled factory environment utilized. An efficient tower crane lifting plan ensures successful high-rise modular project completion. For improved efficiency, the lifting plan should minimize the reaching distance of the tower crane, because this distance directly affects the tower crane capacity, which is directly related to crane operation cost. In situations where units are lifted from trailers, the trailer-to-tower crane distance can have a significant impact on the tower crane operation efficiency. However, optimization of this distance to improve efficiency has not been sufficiently considered. This research proposes a genetic algorithm optimization model that suggests optimized tower crane and trailer locations. The case study results show that through the proposed model, the project manager can reflect the optimal location selection and optimal tower crane selection options with minimal cost.
\end{abstract}

Keywords: modular construction; tower crane; lifting plan; optimization; genetic algorithm (GA), high-rise construction

\section{Introduction}

Modular buildings consist of prefabricated room-sized units that are produced in factories [1]. Modular construction has benefits of improved productivity, short construction period, high quality, and project safety due to the use of controlled factory work environments [2-4]. Although the modular construction method benefits from manufacturing in factories, even in a highly modular project, a significant proportion of the work is still conducted on-site [1]. In the planning of high-rise modular project on-site work, the selection and positioning of tower cranes on the construction site are essential because heavy units have to be lifted [5-7]. In stick-built construction, the major objectives of a tower crane operation plan are minimization of the operating cost, transportation time, and possibility of conflict by adjusting the weight of the material package or modifying the lifting point. Then, the location is selected depending on the objectives [8-10]. However, in modular construction on-site work, the tower crane capacity is directly related to operational efficiency such as cost; therefore, the objective of the operation plan should focus on reducing the tower crane capacity. This is because the weight of the material cannot be adjusted as heavy units cannot be divided. In addition, because the tower crane is usually used for unit lifting, the supply and demand points cannot be modified. Therefore, the capacity affects cost more than the operational time and the total tower crane transportation distance.

During the tower crane operational planning, the capacity is estimated based on a combination of the maximum distance where the tower crane should reach and the weight 
of the material. For high-rise modular projects in urban areas, the units are transported to their destinations by tower cranes from trailers parked nearby because of space constraints. The distance from the trailer parking location to the tower crane can be greater than the distance from the tower crane to the destination of the unit. In this situation, if the tower crane location is selected without a computer-aided calculation method considering trailer location, the tower crane capacity can be overestimated to prevent the situation in which the units cannot be lifted.

However, the trailer parking location has not been considered as a major variable in tower crane location planning for modular construction [5-12]. To overcome the limitations this research focuses on single tower crane location optimization considering the trailer location and destination of each unit. Further, the tower crane capacity is estimated according to the optimized location and unit weight. To achieve these objectives, an extensive literature review is conducted to analyze the important factors that should be considered in tower crane location planning for heavy unit lifting. Then, using a genetic algorithm (GA), an optimization model is developed for optimal tower crane location and tower crane capacity determination. Finally, to validate this optimization model, a case study is conducted. In this research, it is assumed that (1) the tower crane is only used for unit lifting, (2) the weight of each unit is uniform, and (3) the capacity is affected only by the reaching distance and weight.

\section{Tower Crane Operation Plan for Stick-Built Construction}

A tower crane is usually located at the optimal position for handling the heavy and bulky materials, and its jib should cover all of the parts of the buildings on the construction site to transport the materials [9]. Therefore, for tower crane location selection on construction sites and capacity estimation, numerous studies have been conducted. To reduce the total material transportation time when using a single tower crane in building construction, mathematical prescriptive optimization models have been proposed [11]. To cover the overall material demand and supply points and to satisfy the excessive needs of tower cranes in large construction projects. Zhang et al. [10] developed a computerized mathematical model that optimizes the location of a group of tower cranes and predicts and minimizes conflicts and interference. The model can be employed to locate the supply and demand points. To improve single tower crane operation optimization results, including the material supply and demand points, Huang et al. [9] proposed a mixed-integer linear model based on the model of [10]. Wu et al. [13] also presented a crane selection algorithm considering the clearance between the boom/jib and lifted material, ground bearing pressure, lifting capacity of the crane, and boom/jib combinations of a lattice boom crane. Wang et al. [14] developed a BIM-based optimization model for automatic optimized tower crane layout generation, including the material supply location. Marzouk and Abubakr [15] proposed a framework for tower crane type, number, and location selection to improve the tower crane utilization rate. Then, to prevent collisions during tower crane operation, a 4D simulation and case study were conducted. Younes and Marzouk [16] proposed Agent-based simulation for tower crane layout planning. This study focused on how construction activity conflicts affect overall tower crane layout planning. Riga et al. [17] suggesting a mathematical model related to cost-optimal positions considering tower crane and storage areas. However, this paper focuses on optimizing the distance between the operation of the tower crane and the storage area, so there is a limitation that the possible range of lifting can be set wider than that of other studies. In the stick-built construction, tower crane location optimization focused on minimizing the operation cost, which is estimated based on the operation time and number of cranes. However, in modular unit lifting, the tower crane operation plan has different optimization objectives. In modular construction on-site work, a tower crane is typically used to lift heavy units that cannot be divided and the crane operation is intermittent. Therefore, to reduce the tower crane operation cost, the tower crane capacity should be minimized by reducing the distance that the crane must reach. 


\section{Tower Crane Operation Plan for Modular Construction}

Many studies have been conducted to improve the operational efficiency of cranes in modular construction on-site work. Lei et al. [18] proposed a method of establishing feasible module lifting paths by using an automated system to reduce the manual pathchecking practice when there are numerous mobile cranes at a congested site. Han et al. [7] presented a visual 3D simulation model for preventing collisions during lifting operations and validating various lifting operation plans for modular on-site work. In these studies, the working radius was considered to be an important factor in crane location for collision prevention, and unit lifting from the trailers was assumed to be conducted near the cranes. Olearczyk et al. [12] proposed a crane selection method and introduced mathematical algorithms for lifting operation planning. In their research, the maximum weight from the pickup point was considered for crane location identification and determination of the location that would minimize the crane capacity. Their study is significant in that the weight and distance were considered as the major factors when planning modular on-site work; however, it is limited in that the distance was estimated without considering the trailer location. Liew et al. [19] emphasize that high-rise modular building projects have a much larger one-time lifting weight than other high-rise building projects, so it is important to be careful when selecting tower crane specifications. In addition, it is proposed to review various alternatives for selecting the location of the tower crane and the modular lifting position by reflecting the site conditions in the early stages of the project. $\mathrm{GOH}$ and Jian et al. [20] proposed a simulation model for mitigating human factor-related safety risk during the modular construction on-site crane lift. This study emphasizes both the risk and importance of modular site installation and is useful in creating a safety management system for crane lifting plans at the project planning stage. However, this study has limitations in its use to create an alternative that can increase the productivity of on-site lifting.

Hussein and Zayed [21] analyzed papers related to crane lifting of modular construction through a mixed review method. In this study, papers related to the lifting of modular construction cranes are increasing every year, and it has been confirmed that most of the studies are focusing on the field of automation to improve lifting efficiency. In particular, unlike mobile cranes, tower cranes have to be operated continuously until the endpoint after installation on-site, so the importance of selecting specifications was emphasized.

To maximize the benefits of modular construction, high-rise building in dense urban areas using modular construction also has been considered and implemented $[1,12,22,23]$. When lifting units for high-rise modular buildings, tower cranes are used because (1) they are suitable for a wide range of work assignments and (2) they are the key apparatus for vertical and horizontal transportation of materials, especially heavy prefabricated units and large panels for the formworks of high-rise buildings $[9,23]$. In the typical modular unit on-site assembly method, the units are lifted directly from the trailers to their destinations [24]. When conducting a high-rise modular building project in a dense urban area, the construction site may not be sufficient to store the prefabricated modular units [22]. Moreover, the trailer transporting the units may not be able to access the construction site, in which case the units are lifted from the trailer outside the construction site. In this situation, the maximum distance to be used for tower crane capacity estimation can change according to the trailer parking location and site conditions. Therefore, an optimization process is needed to reduce the maximum distance and the distance must be estimated by adjusting the alternatives of tower crane and trailer parking location.

\section{Methodology}

\subsection{Optimization Methodology}

There is numerous research methodology related to optimization keywords; such as mixed-integer linear programming, ant colony optimization, particle swarm optimization, and colliding bodies optimization. In mixed-integer linear programming, it has the advantage of being able to draw accurate conclusions according to mathematical formulas. In 
particular, this method can pre-set a reference value for the choice of an alternative, so that a common conclusion can be reached on the interpretation of the results [25-27]. However, this method has a disadvantage in that it takes too much time to derive an optimization result, and it is difficult to accurately make a mathematical model that implements an optimization model to solve the problem $[28,29]$. The ant colony optimization (ACO) also applies to optimization problems, such as the traveling salesman problem (TSP). However, the ACO has a limitation in that there are many parameter values and reacts too sensitively to the parameters, so that the deviation of the result values may increase [30]. The particle swarm optimization (PSO) is one of the wide-area optimization methods and finally achieves objective function optimization by simultaneously improving candidate solutions through iterative calculations. However, PSO is based on a completely different concept from genetic algorithms. This focuses on the characteristics of the individuals within the target group and the exchange of information between them. Therefore, it is difficult to derive an internal condition search result that considers both the optimal distance condition and the physical constraint condition of the tower crane and the modular lift position [31]. In addition, there are powerful new optimization research methods of Colliding Bodies Optimization (CBO) and Vibrating Particles Systems (VPS), but these have a problem that it is difficult to express the tower crane lifting condition and trailer position relatively simply and easily [32,33].

When performing tower crane location selection, it is necessary to consider variables such as the trailer location, destinations of the units, and alternative tower crane locations simultaneously. Therefore, a methodology that can optimize multiple variables is needed. A genetic algorithm (GA) is frequently used to solve such optimization problems. GA solves optimization problems by applying the principle of evolution, in which only the object most suitable for the considered environment survives [34]. The optimization procedure is implemented in the form of evolving genes through processes such as selection, crossover, and mutation. In the GA reproduction process, the best-fit solution has a few chances for reproduction, whereas the least-fit solution may not reproduce at all. By repeating this reproduction process, the optimization outcome is improved. In the GA optimization process, the solutions of any problems can be represented by sets of parameters. These parameters are defined as the genes of chromosomes and can be structured by strings of values in the binary form [35]. Therefore, a GA is effective for solving combinatorial and discrete optimization problems and can also be used to solve mixed-discrete nonlinear optimization problems [36]. Thus, it is suitable for solving the combinatorial optimization problem in this research. The framework of the optimization model is shown in Figure 1.

\subsection{Input Data Representation for Model}

The first steps in developing the model are to (1) represent the site conditions as ( $x, y)$ coordinates and (2) to use the coordinates as input data. In this research, the site is gridded and $0.5 \mathrm{~m}$ is set as the base unit of the width and height for the $(\mathrm{x}, \mathrm{y})$ coordinates. The first reason for doing so is that the sizes of the modular units assumed in this research vary, including $3 \mathrm{~m} \times 6 \mathrm{~m}, 3 \mathrm{~m} \times 9 \mathrm{~m}$, and $2 \mathrm{~m} \times 6 \mathrm{~m}$. When identifying the centers of gravity of the units, $0.5 \mathrm{~m}$ is the maximum width and height unit. The second reason is that, if the coordinate interval is increased, the spatial efficiency of the construction site decreases because the amount of dead space would also increase. Then, the site at which the building is constructed and the carriageway for the trailer location are separated to implement the assumption that the trailer cannot enter the construction site. To increase the model efficiency, the areas where units cannot be installed, the tower crane cannot be located, or the trailer cannot be parked, are excluded from the model. Figure 2 shows an example of site representation using coordinates. After representing the site conditions using coordinates, three variables related to tower crane and trailer location selection are identified. The first variable is the location at which a particular modular unit is to be installed, and the second variable is the installation location of the tower crane. Even though it is considered that the modular units and tower crane can be located anywhere on 
the construction site, in this case, this model can consider the design to determine the tower crane location when a building design is an input, as shown in the case study. The last variable is the trailer location and the trailer is located on the road near the construction site. The distance between the tower crane and trailer and between the tower crane and unit destination is estimated by calculating the distance between the coordinates. Then, as building information data, the unit weight and building height are input to obtain tower crane specification suggestions. Finally, to identify the tower cranes satisfying the lifting conditions, a tower crane database comprising data such as self-reliance height, tip-load, and the rental fee is established. Based on the above-mentioned data, suggested tower crane and trailer locations and tower crane specifications are obtained by implementing the data processing approach described in the next section.

\subsection{Data Processing for Location Selection}

After identifying the input data and variables, data processing for the tower crane and trailer location selection is conducted. To estimate the tower crane capacity, two distances are calculated using the tower crane, trailer, unit location variables: (1) the distance from the trailer to the tower crane and (2) the distance from the units to the tower crane, as shown in Figure 3. Considering the location variables, the greatest distance that the tower crane should reach for lifting is derived, and to minimize this distance, optimization is conducted by using the GA in Step 1 of the model framework. Equation (1) is the optimization object employed to reduce the greatest distance.

$$
\min [\max \{\text { Tower Crane, Trailer\}, } \max \{\text { Tower Crane, Units\}] }
$$

To minimize the greatest distance using the GA, the variables indicated using coordinates, such as the tower crane, unit, and trailer locations, are converted into chromosomes. Figure 4 shows the definition of the chromosome structure. The chromosome length $(\mathrm{P})$ is defined as the sum of the number of locations with coordinates at which the tower crane can be located $(\mathrm{Pc})$ and the number of locations with coordinates at which the trailer can be located $(\mathrm{Pt})$. The gene is defined as the number of tower cranes located at the coordinates. For example, when the tower crane is located at Px, the gene is expressed as " 1 "; otherwise, the gene is expressed as " 0 ". The trailer location genes are represented in the same way as those of the tower crane. In this research, it is assumed that a single tower crane and trailer could be located, so the sum of the gene values is two. The genes act as variables for deriving the optimal tower crane and trailer parking locations depending on the unit installation locations. The optimization results can be improved by iteratively combining the tower crane and trailer parking locations, and better results can be obtained by increasing the number of iterations.

After optimizing the two distances, the tower crane capacity can be estimated by using the greatest distance and maximum weight of each unit. Then, from a database including the maximum tip-load according to distance, self-reliance height, and rental fee, a suggested tower crane model and specifications satisfying the lifting capacity can be obtained. Among the suggested tower cranes, those with self-reliance heights greater than the building height are listed as shown in Step 2 of the model framework. In general, if a tower crane satisfying the conditions does not exist or the unit weights change, it is necessary to return to the first step to reselect a tower crane with changing input data such as site conditions and input more tower cranes into the database. Then, the model results provide tower crane and trailer locations as well as tower crane specifications such as capacity, self-reliance height, and rental fee. Moreover, if multiple tower cranes are suggested, the tower cranes are ranked according to the rental fee to inform decisions regarding the on-site work plan. 

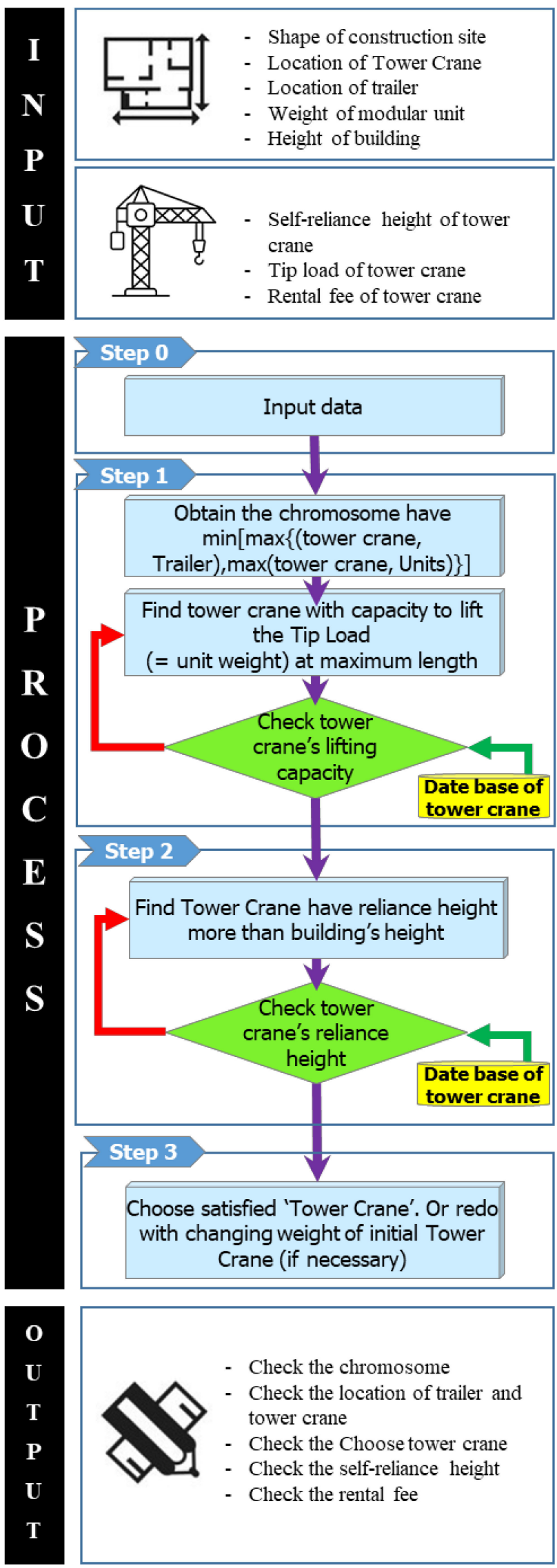

Figure 1. Tower crane selection model framework. 


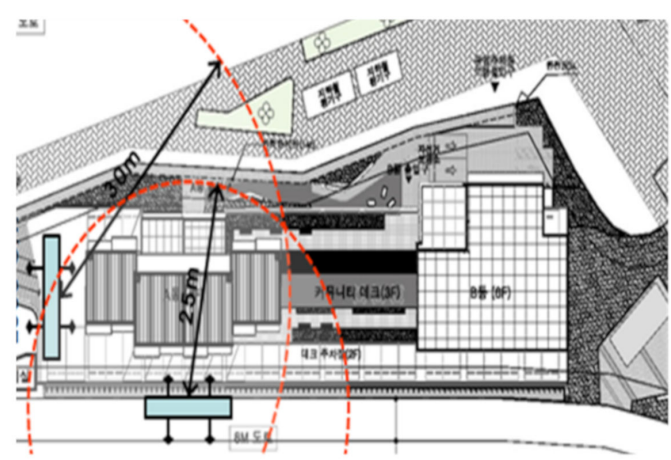

(a)
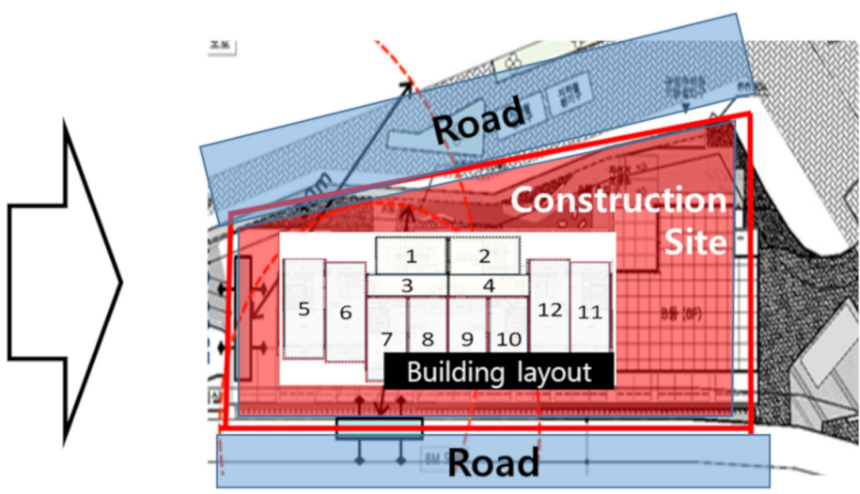

(b)

Figure 2. Conversion of site conditions into coordinates (legend: (a) is the initial construction plan, (b) is the road shape and building layout area of the initial construction plan).

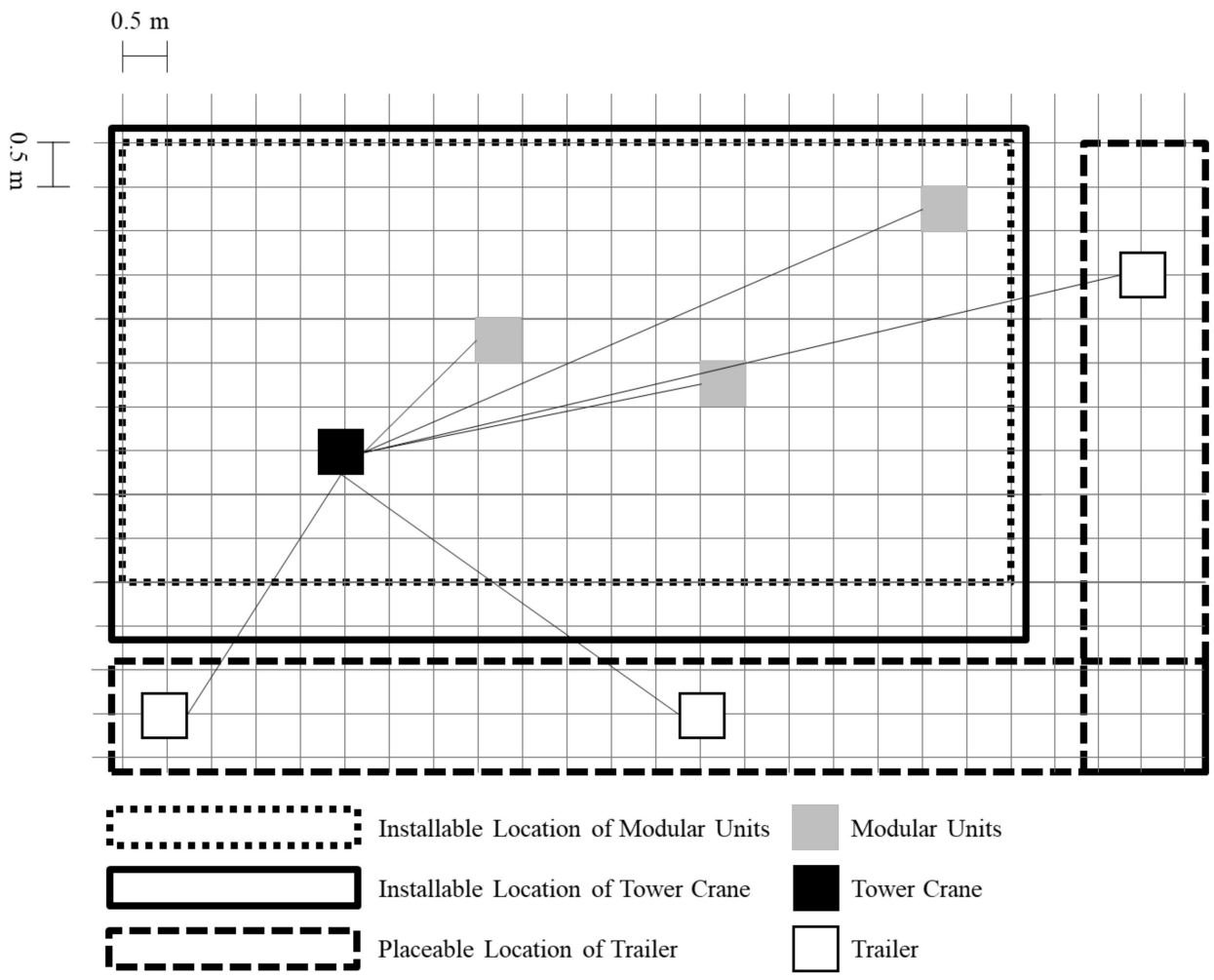

Figure 3. Distance estimation.

$$
\begin{gathered}
P=P_{c}+P_{t}=2 \\
P_{c}=P_{c 1}+P_{c 2}+\cdots+P_{c m-1}+P_{c m}=1 \\
P_{t}=P_{t 1}+P_{t 2}+\cdots+P_{t n-1}+P_{t n}=1
\end{gathered}
$$

$P:$ Length of gene

$P_{c}:$ Installable location of $\mathrm{T} / \mathrm{C}$

$P_{t}$ : Placeable location of Trailer

Installable location of T/C Placeable location of Trailer

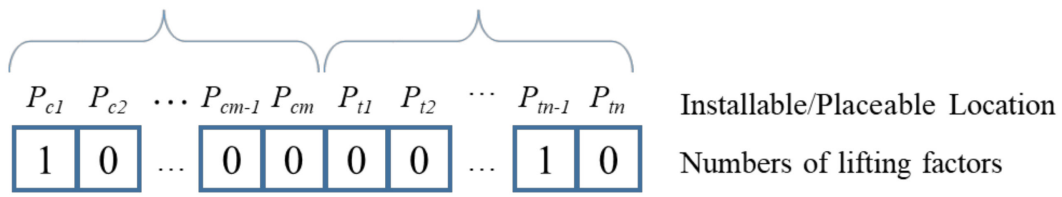

Figure 4. Definition of chromosome structure. 


\section{Case Study}

This section presents the case study conducted to validate the model for tower crane and trailer location selection in a high-rise modular building project by comparing the greatest distance in the initial tower crane operation plan and the greatest distance in the optimization results. The selected project is a modular apartment building that has not yet been constructed and the initial tower crane and trailer locations in the on-site work plan are used in the case study. Table 1 provides a profile of the case project. The case project is a seven-story modular building consisting of 62 units of two types $(3 \mathrm{~m} \times 6 \mathrm{~m}$, $2 \mathrm{~m} \times 6 \mathrm{~m}$ ), and to lift the units. To ensure the use of a tower crane, the number of stories in the building is increased from seven to fifteen $(45 \mathrm{~m}$, where the height of each floor is about $3 \mathrm{~m}$ ). Also, in this study, to optimize the tower crane, only the physical conditions (the arrangement of modular buildings, the distance between the road and the building) are maintained among the existing building conditions, and the liftable areas (the location of the tower crane installation, the location of the trailer) are all areas that can be used. In the tower crane database, the product name of the tower crane changes the luffing type and $t$-type tower crane as follows; luffing type $a$, luffing type $b$.

Table 1. Revised case study project information.

\begin{tabular}{|c|c|c|}
\hline Contents & $\begin{array}{c}\text { Initial Modular } \\
\text { Project Information }\end{array}$ & Revised Modular Project Information \\
\hline Location & \multicolumn{2}{|c|}{ Seoul, South Korea } \\
\hline Site Area & \multicolumn{2}{|c|}{$3070.50 \mathrm{~m}^{2}$} \\
\hline Purpose & \multicolumn{2}{|c|}{ Multi-Purpose Building (Apartment, Commercial) } \\
\hline Story & 7 Stories & 15 Stories \\
\hline Height & $27 \mathrm{~m}$ & $45 \mathrm{~m}$ \\
\hline No. of Units & \multicolumn{2}{|c|}{62 units } \\
\hline Maximum Weight & \multicolumn{2}{|c|}{14 ton (Unit: 12 ton, Balance Beam: 2 ton) } \\
\hline
\end{tabular}

The coordinates of the centers of the weight of the modular units are included as reference points to estimate the distance from the tower crane. After inputting the weight, the tower crane and trailer locations are selected by using the GA. Based on the estimated values such as weight and locations, tower crane specifications satisfying the lifting condition are derived from the database. By comparing the tower crane self-reliance and building heights, tower crane models are identified. Among the listed tower cranes, the tower crane with the lowest capacity and rental fee is suggested.

For the optimization analysis, in this study, the site conditions were plotted based on the initial modular construction plan. First, the road conditions and the shape of the site are extracted, and then the building layout plan is reflected. The extracted schematic part is applied with a grid so that the $\mathrm{x}, \mathrm{y}$ coordinates can be set to enable GA analysis, and these coordinates are divided into the following areas; Trailer navigation area, tower crane navigation area (Figure 5).

Considering the working characteristics of the luffing tower crane, this crane can only vertically move and rotate the lifted object, and it cannot be moved horizontally using a trolley in the field like a T-type tower crane as shown in Table 2. Therefore, it is necessary to give the minimum clearance distance from the result of calculating the maximum lifting distance and height. In this case, for example, if the initial maximum distance of $15.4 \mathrm{~m}$ is obtained, the minimum jib length of the crane should be $20 \mathrm{~m}$. On the other hand, following the result of this study, a jib length of $15 \mathrm{~m}$ is sufficient for $12.9 \mathrm{~m}$. As mentioned above, the result of minimizing the minimum jib length of the luffing tower crane used in urban dense construction can improve construction efficiency and reduce costs.

After setting the search condition, for tower crane and trailer location optimization, Evolver 5.5 and Microsoft Excel 2010 software are employed. The initial population size is 100 , and the mutation rate is set to 0.1 . At this time, uniform crossover calculations are performed with the crossover rate set to 0.5 . Based on the given optimization condition, the 
optimization results are derived. As a result, the optimal location of the tower crane and trailer was derived to the south of the building, and the most suitable tower crane specifications were also selected (Figure 6). When comparing the specifications and rental costs of the top 10 tower cranes selected based on the location, it was confirmed that the difference in rental costs between the rank 1 and rank 10 places was $\$ 16,361 /$ month (Table 3 ). In this study, many assumptions and restrictions were placed for the selection of the optimal location of the tower crane for a high-rise modular building, but it was confirmed that cost loss, as well as efficient construction management, was difficult if the optimal alternative was not selected at the same location through case studies. In particular, through this result, it was confirmed that if rank 1 is not rented during the actual construction period, it can be used as basic data for selecting the specifications of rank 2 and rank 3 immediately.

In particular, considering the relationship between the jib length of the top three tower cranes and the tip rod, the optimal location of the tower crane in a high-rise modular construction will lead to a problem in which a completely new type of tower crane can be searched as long as the modular weight cannot be changed (Figure 7).

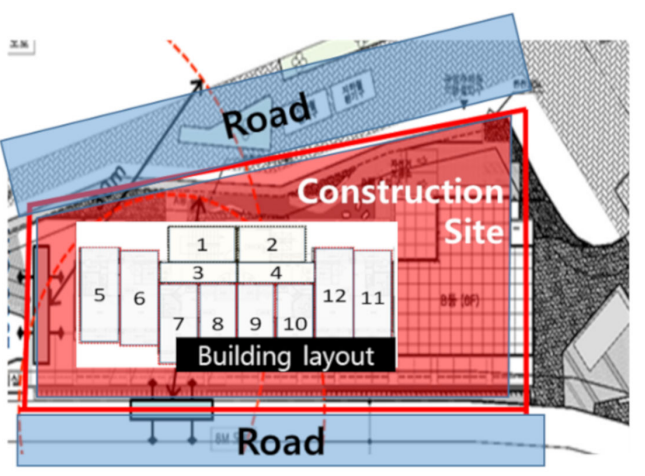

(a)

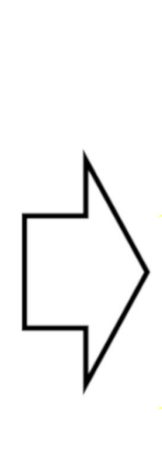

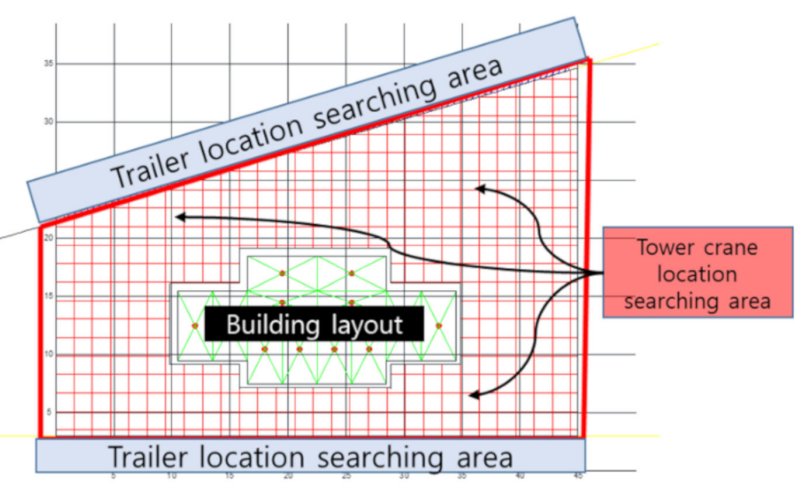

(b)

Figure 5. Set a tower crane and trailer location searching area based on the initial construction plan (legend: (a) is the road shape and building layout area of the initial construction plan, (b) is the search area for optimization).

Table 2. Tower crane types and features.

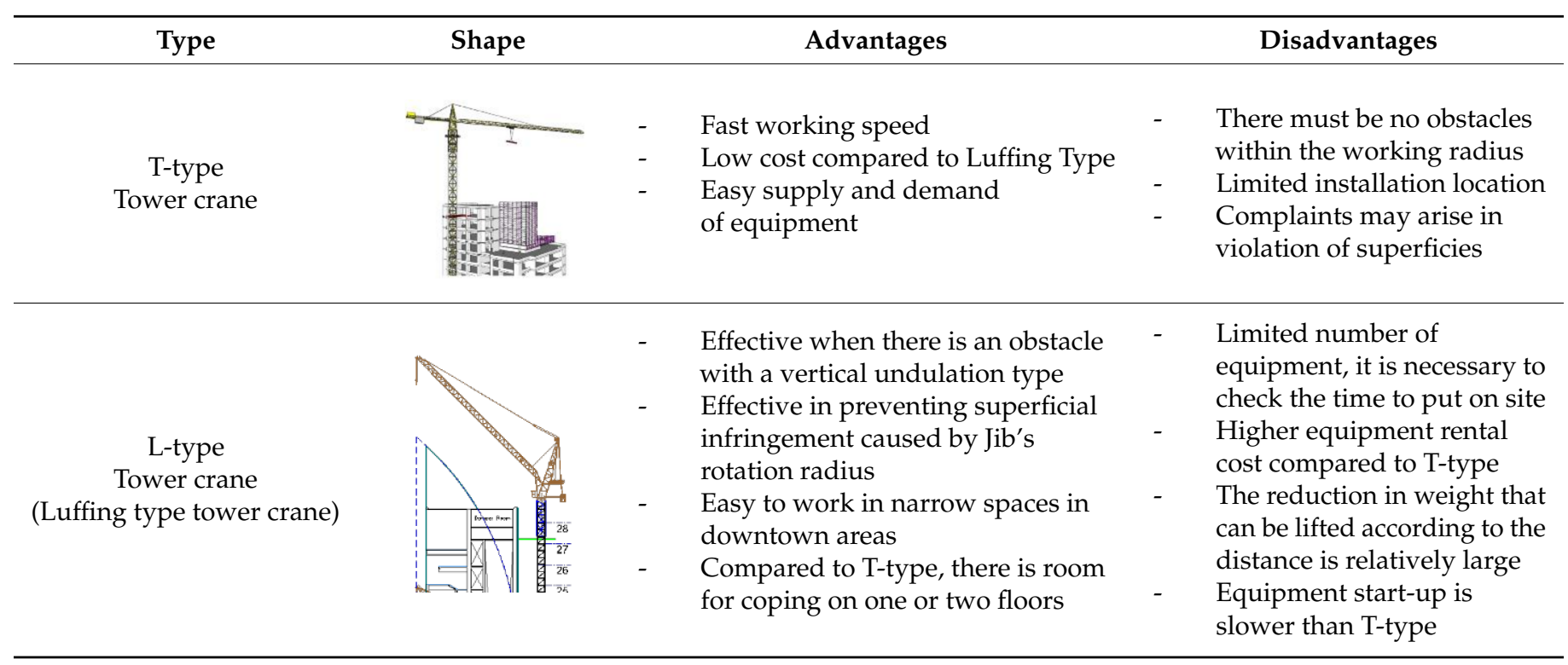




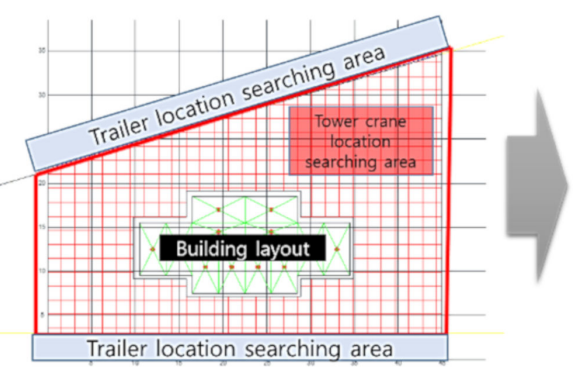

(a)

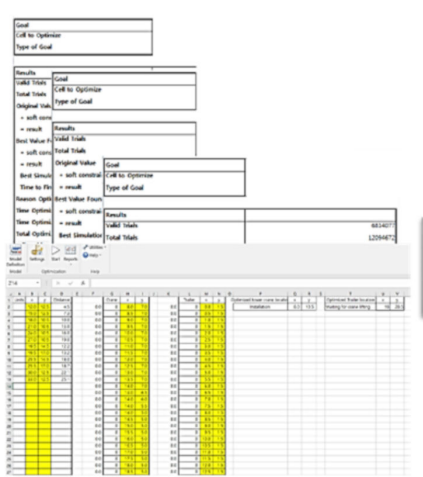

(b)

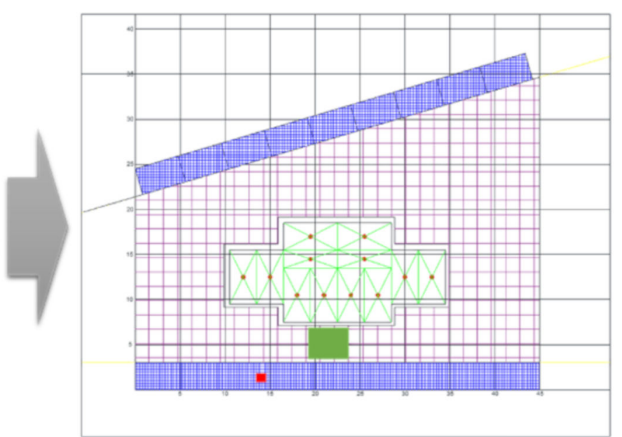

(c)

Figure 6. Finding the optimal location for tower crane and trailers (legend: (a) is the search area for the genetic algorithm (GA) optimization, (b) is the GA search results report summary, (c) is the optimal position of the tower crane and trailer after the end of the search (green box: tower crane position, red sphere: trailer position)).

Table 3. Optimization results and suggested tower cranes.

\begin{tabular}{cccccc}
\hline Rank & $\begin{array}{c}\text { Tower Crane } \\
\text { Type }\end{array}$ & $\begin{array}{c}\text { Optimized Maximum } \\
\text { Jib Length } \\
\text { (Unit: Meter) }\end{array}$ & $\begin{array}{c}\text { Tower Crane } \\
\text { Self-Reliance Height in } \\
\text { Optimized Positon } \\
\text { (Unit: Meter) }\end{array}$ & $\begin{array}{c}\text { MAXIMUM Lifting } \\
\text { Weight in Optimized } \\
\text { Position } \\
\text { (Unit: Ton) }\end{array}$ & $\begin{array}{c}\text { Rental Cost } \\
\text { (Unit: \$/Month) }\end{array}$ \\
\hline 1 & Luffing Type & 16.0 & 58.7 & 16.0 & 14,300 \\
2 & Luffing Type & 16.0 & 64.9 & 16.0 & 14,019 \\
3 & Luffing Type & 19.2 & 58.7 & 19.2 & 17,513 \\
4 & Luffing Type & 24.0 & 74.0 & 24.0 & 21,024 \\
5 & Luffing Type & 24.0 & 53.3 & 23.0 & 21,454 \\
6 & Luffing Type & 23.0 & 59.1 & 23.0 & 24,080 \\
7 & Luffing Type & 22.5 & 59.1 & 32.5 & 24,518 \\
8 & Luffing Type & 32.0 & 77.8 & 32.0 & 28,021 \\
9 & Luffing Type & 32.0 & 74.4 & 27.5 & 30,649 \\
10 & Luffing Type & 27.5 & 53.3 & & 30,661 \\
\hline
\end{tabular}

(Unit: Tons)

25.0

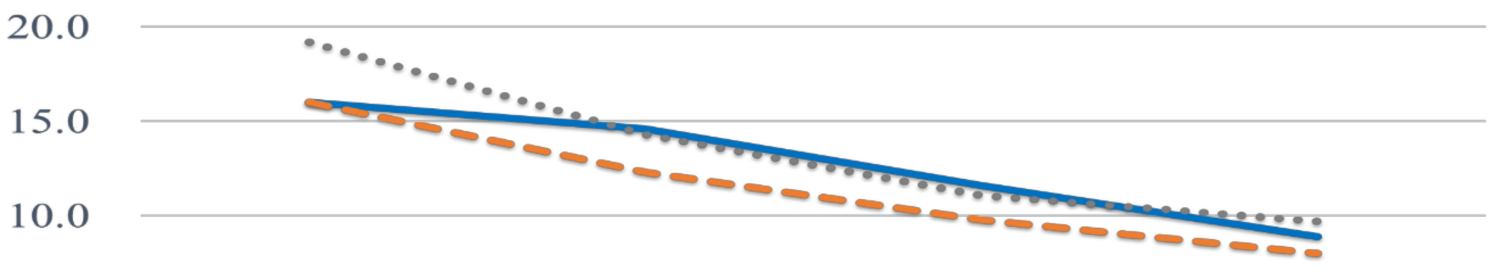

5.0

0.0

\begin{tabular}{|c|c|c|c|}
\hline Loads & Loads & Loads & Loads \\
Jib=15meter & Jib=20meter & Jib=25meter & Jib=30meter
\end{tabular}

-Rank 1 -Rank 2 ... Rank 3

Figure 7. The relationship between the change in jib length and maximum lifting loads following from rank 1 to 3 tower crane's specifications. 


\section{Discussion}

In general, the final goal of the tower crane location optimization study can be divided into improving the lifting efficiency and minimizing the operating cost. It is assumed that the weight of the object being lifted can be partially adjusted once, and the location of the yard reflects the characteristics of repeating creation and destruction depending on whether or not materials are used. After this process, the contractor manager or construction manager finds and contracts a tower crane that can be rented during the lifting period based on the minimum performance condition of the tower crane derived from the research results. In the case of high-rise modular construction projects, the construction period is shorter than that of conventional construction projects of similar size, and the proportion of the total construction occupied by the load on the site is larger. In addition, the controllable part of one-time lift weight is limited and heavy, so the selection and location of the tower crane specifications optimized with limited information in the early stages of construction are very important for successful project completion. Previous studies related to the selection and optimization of tower cranes in high-rise modular construction also highlighted this point. However, these studies had limitations in adjusting the position of the trailer to fit the modular size or reflecting the point that the position of the tower crane can change according to the change in the arrangement of the modular building. So, this study focused on developing a framework that could provide the project manager with the tower crane specifications and location with limited information in the early stages of the project. First of all, the trailer location was first considered during the initial lift planning stage. By placing the trailer near the tower crane, the distance from the tower crane to the trailer could be reduced. However, the greatest distance differs between the initial and optimized lifting plans even with a simple site shape and building design.

The findings demonstrate that accurate results can be obtained by computer-aided modeling and that the difference between the greatest distances can cause tower crane capacity overestimation. In heavy unit lifting, distance reduction is important because the distance is directly related to the tower crane operation efficiency. Moreover, the more complicated the site and building shape is, the more difficult it is to select the optimal tower crane and trailer locations and the more effective the model employed in this research.

If the specifications of the selected tower crane cause the determined operation cost range to be exceeded, the construction manager can change the tower crane capacity by modifying the unit weight. Unit weight modification also requires consultation among the project participants, and the model developed in this research can be an effective tool during this process. By applying this model, the time and cost, which must be considered during planning, can be reduced and other optimized alternatives can be achieved easily. In a dense urban area, it may not be possible for the trailer to be located at the optimal location or the location may change according to permits for traffic control during on-site unit lifting. By using the model developed in this research, alternatives can be suggested based on the tower crane operation efficiency by excluding the locations at which the trailer cannot be placed.

\section{Conclusions}

Modular construction involves unit manufacturing and on-site work and can be employed in high-rise building construction. Modular unit lifting in high-rise modular projects is considered to be important because heavy units have to be installed in dense urban construction sites. In unit lifting, a high-capacity tower crane is used and the tower crane location cannot be modified; therefore, the tower crane location should be planned such that it can be performed with minimized operational cost. In tower crane operation plans for modular projects, the tower crane capacity is directly related to the operational cost and the distance from the tower crane to the object and unit weight are key factors that can be employed to estimate the tower crane capacity. In modular tower crane operation planning, the trailer location also should be considered when estimating the 
greatest distance because there may not be sufficient space for the trailers transporting units. Therefore, in this research, an optimization model for distance minimization considering the tower crane and trailer locations that can suggest tower crane and trailer locations for on-site unit lifting is developed. Then, a case study is conducted to validate the proposed model. Moreover, in projects conducted at sites with complicated shapes, it is expected that the model results will differ significantly and will be useful for tower crane and trailer location selection. According to this research, the tower crane capacity can be estimated accurately by considering the tower crane and trailer locations and can be reduced. The optimization model can be employed to design building layout planning considering tower crane operation plans or when changing trailer locations during on-site construction. This research also has academic value. When deriving optimization results, several variables should be considered and the process includes a number of combinatorial results and results comparison. By using the optimization model developed in this research, the results comparison process can be conducted automatically and the efficiency of the tower crane location optimization process can be improved.

However, this research has certain limitations. Firstly, only a single tower crane and single trailer location are considered, although multiple cranes can be effective in some cases. Secondly, changes according to on-site work progress are not considered, although other conditions such as the trailer location and unit weight could be modified and the optimization process conducted again. Finally, the connection between the tower crane and building core for capacity reduction is not considered. In future research, the model will be extended to overcome these limitations to further improve the efficiency of on-site lifting operations using Colliding Bodies Optimization and Vibrating Particle System.

Also, it is necessary to derive results reflecting the weight of each unit not uniform, and capacity to be affected by other factors (i.e., changes according to on-site progress).

Author Contributions: Conceptualization, J.L., M.P. and D.L.; methodology, D.L. and H.H.; software, D.L. and H.H.; validation, J.L. and D.L.; formal analysis, J.L. and D.L.; investigation, H.H.; resources, D.L.; data curation, H.H.; writing—original draft preparation, H.H. and D.L.; writing-review and editing, J.L. and M.P.; visualization, H.H.; supervision, J.L.; project administration, M.P. All authors have read and agreed to the published version of the manuscript.

Funding: This research received no external funding.

Institutional Review Board Statement: Not applicable.

Informed Consent Statement: Not applicable.

Data Availability Statement: The data that support the findings of this study are available from the corresponding author upon reasonable request.

Acknowledgments: This work was supported by Gyeongsang National University Grant in 2020 2021.

Conflicts of Interest: The authors declare no conflict of interest.

\section{References}

1. Lawson, R.M.; Ogden, R.G.; Bergin, R. Application of Modular Construction in High-Rise Buildings. J. Arch. Eng. 2012, 18, 148-154. [CrossRef]

2. Eastman, C.M.; Sacks, R. Relative Productivity in the AEC Industries in the United States for On-Site and Off-Site Activities. J. Constr. Eng. Manag. 2008, 134, 517-526. [CrossRef]

3. Mullens, M.A. Factory Design for Modular Homebuilding: Equipping the Modular Factory for Success; CRC Press: Boca Raton, FL, USA, 2011.

4. Shaked, O.; Warszawski, A. CONSCHED: Expert System for Scheduling of Modular Construction Projects. J. Constr. Eng. Manag. 1992, 118, 488-506. [CrossRef]

5. Al-Hussein, M.; Alkass, S.; Moselhi, O. An algorithm for mobile crane selection and location on construction sites. Constr. Innov. 2001, 1, 91-105. [CrossRef]

6. Han, S.; Al-Hussein, M.; Hasan, S.; Gokce, K.U.; Bouferguene, A. Simulation of mobile crane operations in 3D space. In Proceedings of the 2012 Winter Simulation Conference (WSC), Berlin, Germany, 9-12 December 2012; pp. 1-12.

7. Han, S.H.; Hasan, S.; Bouferguène, A.; Al-Hussein, M.; Kosa, J. Utilization of 3D Visualization of Mobile Crane Operations for Modular Construction On-Site Assembly. J. Manag. Eng. 2015, 31, 04014080. [CrossRef] 
8. Alkriz, K.; Mangin, J.C. A new model for optimizing the location of cranes and construction facilities using genetic algorithms. In Proceedings 21st Annual ARCOM Conference, London, UK, 7-9 September 2005; Springer: Berlin/Heidelberg, Germany, 2005; pp. 981-991.

9. Huang, C.; Wong, C.; Tam, C. Optimization of tower crane and material supply locations in a high-rise building site by mixed-integer linear programming. Autom. Constr. 2011, 20, 571-580. [CrossRef]

10. Zhang, P.; Harris, F.C.; Olomolaiye, P.O.; Holt, G.D. Location Optimization for a Group of Tower Cranes. J. Constr. Eng. Manag. 1999, 125, 115-122. [CrossRef]

11. Rodriguez-Ramos, W.E.; Francis, R.L. Single Crane Location Optimization. J. Constr. Eng. Manag. 1983, 109, 387-397. [CrossRef]

12. Olearczyk, J.; Al-Hussein, M.; Bouferguène, A. Evolution of the crane selection and on-site utili-zation process for modular construction multilifts. Autom. Constr. 2014, 43, 59-72. [CrossRef]

13. Wu, D.; Lin, Y.; Wang, X.; Wang, X.; Gao, S. Algorithm of Crane Selection for Heavy Lifts. J. Comput. Civ. Eng. 2011, 25, 57-65. [CrossRef]

14. Wang, J.; Zhang, X.; Shou, W.; Wang, X.; Xu, B.; Kim, M.J.; Wu, P. A BIM-based approach for automated tower crane layout planning. Autom. Constr. 2015, 59, 168-178. [CrossRef]

15. Marzouk, M.; Abubakr, A. Decision support for tower crane selection with building information models and genetic algorithms. Autom. Constr. 2016, 61, 1-15. [CrossRef]

16. Younes, A.; Marzouk, M. Tower cranes layout planning using agent-based simulation considering activity conflicts. Autom. Constr. 2018, 93, 348-360. [CrossRef]

17. Riga, K.; Jahr, K.; Thielen, C.; Borrmann, A. Mixed integer programming for dynamic tower crane and storage area opti-mization on construction sites. Autom. Constr. 2020, 120, 103259. [CrossRef]

18. Liew, J.; Chua, Y.; Dai, Z. Steel concrete composite systems for modular construction of high-rise buildings. Structures 2019, 21, 135-149. [CrossRef]

19. Goh, J.; Hu, S.; Fang, Y. Human-in-the-Loop Simulation for Crane Lift Planning in Modular Construction On-Site Assembly. In Computing in Civil Engineering 2019; American Society of Civil Engineers (ASCE): Atlanta, GA, USA, 2019; pp. 71-78.

20. Hussein, M.; Zayed, T. Crane operations and planning in modular integrated construction: Mixed review of literature. Autom. Constr. 2021, 122, 103466. [CrossRef]

21. Lei, Z.; Taghaddos, H.; Olearczyk, J.; Al-Hussein, M.; Hermann, U. Automated Method for Checking Crane Paths for Heavy Lifts in Industrial Projects. J. Constr. Eng. Manag. 2013, 139, 04013011. [CrossRef]

22. Jaillon, L.; Poon, C. The evolution of prefabricated residential building systems in Hong Kong: A review of the public and the private sector. Autom. Constr. 2009, 18, 239-248. [CrossRef]

23. Lawson, M.; Ogden, R.; Goodier, C. Design in Modular Construction; CRC Press: Boca Raton, FL, USA, 2014.

24. Smith, R.E. Prefab Architecture: A Guide to Modular Design and Construction; John Wiley \& Sons: Hoboken, NJ, USA, 2011.

25. Sangaiah, A.K.; Tirkolaee, E.B.; Goli, A.; Dehnavi-Arani, S. Robust optimization and mixed-integer linear programming model for LNG supply chain planning problem. Soft Comput. 2019, 24, 7885-7905. [CrossRef]

26. Batur, M.E.; Cihan, A.; Korucu, M.K.; Bektaş, N.; Keskinler, B. A mixed integer linear programming model for long-term planning of municipal solid waste management systems: Against restricted mass balances. Waste Manag. 2020, 105, 211-222. [CrossRef]

27. Meng, L.; Zhang, C.; Ren, Y.; Zhang, B.; Lv, C. Mixed-integer linear programming and constraint programming formula-tions for solving distributed flexible job shop scheduling problem. Comput. Ind. Eng. 2020, 142, 106347. [CrossRef]

28. Rahnamayan, S.; Tizhoosh, H.R.; Salama, M.M. A novel population initialization method for accelerating evolutionary algorithms. Comput. Math. Appl. 2007, 53, 1605-1614. [CrossRef]

29. Anvari, B.; Angeloudis, P.; Ochieng, W. A multi-objective GA-based optimisation for holistic Manufacturing, transportation and Assembly of precast construction. Autom. Constr. 2016, 71, 226-241. [CrossRef]

30. Treviño, C.A. Single Tower Crane Allocation Models Using Ant Colony Optimization; The University of Texas Rio Grande Valley: Ann Arbor, MI, USA, 2017.

31. Adrian, A.M.; Utamima, A.; Wang, K.-J. A comparative study of GA, PSO and ACO for solving construction site layout optimization. KSCE J. Civ. Eng. 2014, 19, 520-527. [CrossRef]

32. Kaveh, A.; Mahdavi, V. Colliding bodies optimization: A novel meta-heuristic method. Comput. Struct. 2014, 139, 18-27. [CrossRef]

33. Kaveh, A.; Ghazaan, M.I. A new meta-heuristic algorithm: Vibrating particles system. Sci. Iran. 2017, 24, 551-566. [CrossRef]

34. Golberg, D.E. Genetic algorithms in search, optimization, and machine learning. Addion Wesley 1989, $102,36$.

35. Tam, C.M.; Tong, T.K.L.; Chan, W.K.W. Genetic Algorithm for Optimizing Supply Locations around Tower Crane. J. Constr. Eng. Manag. 2001, 127, 315-321. [CrossRef]

36. Sawhney, A.; Mund, A. Adaptive Probabilistic Neural Network-based Crane Type Selection System. J. Constr. Eng. Manag. 2002, 128, 265-273. [CrossRef] 